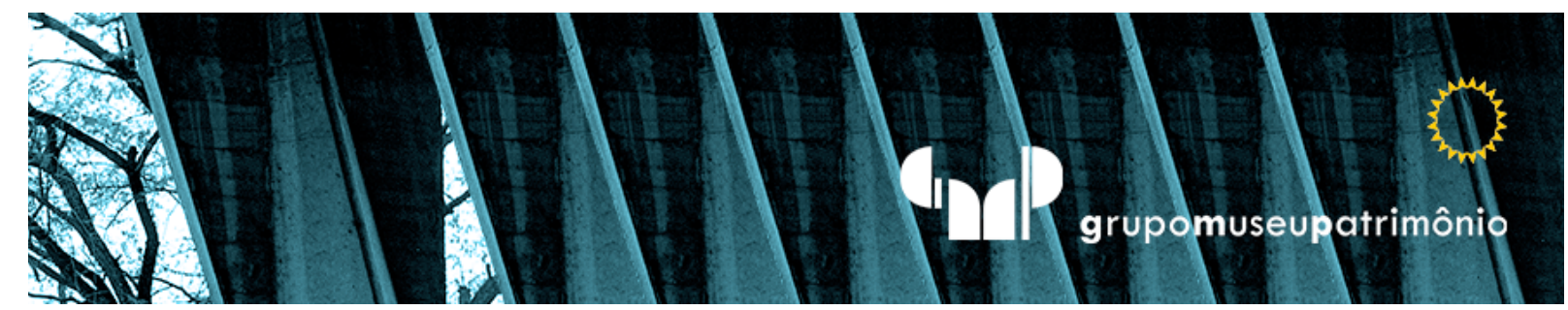

\title{
Square Depression de Bruce Nauman: a experiência no espaço público
}

Square Depression de Bruce Nauman: la experiencia en el espacio público

\section{Bruce Nauman's Square Depression: the experience in public space}

Mayra Simone dos Santos

Doutoranda FAU USP, São Paulo,Brasil.mayrasantos@usp.br 


\section{Resumo}

Este artigo trata da análise de Square Depression de Bruce Nauman, uma escultura que reaviva o debate sobre aproximação da arte com a arquitetura no espaço público. Uma obra que se desenvolve no chão, construindo uma nova topografia no espaço urbano e trazendo uma experiência diferente no cenário artístico com relação aos domínios público e privado. $O$ trabalho procura também enquadrar a obra dentro do panorama das esculturas do artista revelando assim seu aspecto único.

Palavras-Chave: Escultura. Espaço Público. Arte. Arquitetura. Experimentação.

\section{Resumen}

Este artículo aborda el análisis de la Square Depression de Bruce Nauman, una escultura que revive el debate sobre el enfoque del arte con la arquitectura en el espacio público. Un trabajo que se desarrolla en el piso, construyendo una nueva topografía en el espacio urbano y aportando una experiencia diferente en la escena artística con respecto a los dominios públicos y privados. La obra también busca enmarcar la obra dentro del panorama de las esculturas del artista, revelando así su aspecto único.

Palavras-Clave: Escultura. Espacio Publico. Arte. Arquitectura.

Experimentación.

\section{Abstract}

This paper deals with the analysis of Bruce Nauman's Square Depression, a sculpture that revives the debate on approach of art with architecture in public space. A work that develops on the floor, building a new topography in the urban space and bringing a different experience in the artistic scene with respect to the public and private domains. The work also seeks to frame the work within the panorama of the artist's sculptures thus revealing its unique aspect.

Keywords: Sculpture. Public place. Art. Architecture. Experimentation. 


\section{INTRODUÇÃO ${ }^{1}$}

o chegarmos em frente ao Instituto de Física Nuclear da Universidade A de Münster na Alemanha, deparamos-nos com uma peça construída em concreto branco, enterrada no solo. Sua forma sugere o negativo de uma pirâmide invertida, com uma base quadrada de $25 \times 25$ metros e profundidade de 2,3 metros no seu centro. Trata-se da escultura pública Square Depression, projetada pelo artista norte-americano Bruce Nauman.

A profundidade anunciada no próprio título da obra só é vivenciada à medida em que adentramos nela. Pode-se pensar no Square - na forma geométrica quadrada, ou na forma antiquada - mas não a vemos, só percebemos a inclinação de seus planos. A superfície branca da escultura entra em contraste com a área gramada, lembrando um grande palco onde o público pode caminhar, fazendo-nos lembrar das rampas e acessos arquitetônicos a exemplo de como enfrentamos os aclives e declives de uma topografia ou

\footnotetext{
${ }^{1}$ O presente trabalho foi realizado sob orientação do Prof. Dr. Carlos Augusto Mattei Faggin, com apoio da Coordenação de Aperfeiçoamento de Pessoal de Nível Superior - Brasil (CAPES) Código de Financiamento 001.
} 
quando as construímos literalmente por uma demanda do espaço ou imposição do programa. Podemos tomar como referência a praça em frente ao Centro Georges Pompidou em Paris, de Richard Rogers e Renzo Piano, caracterizada ao mesmo tempo enquanto praça inclinada e rampa de acesso, cuja inclinação e tamanho determinam o modo de ver o espaço ao redor. Os planos inclinados tanto de Bruce Nauman, quanto de Richard Rogers e Renzo Piano, parecem agir da mesma forma, mesmo estando em campos diferentes. O que os diferenciam é que no caso da escultura de Nauman, os planos inclinados, acessados por quaisquer lados, levam ao centro da obra, refletindo seu caráter autorreferente, enquanto a rampa do Centro Georges Pompidou é uma praça e também acesso ao edifício, ou seja, um elemento que faz parte do todo.

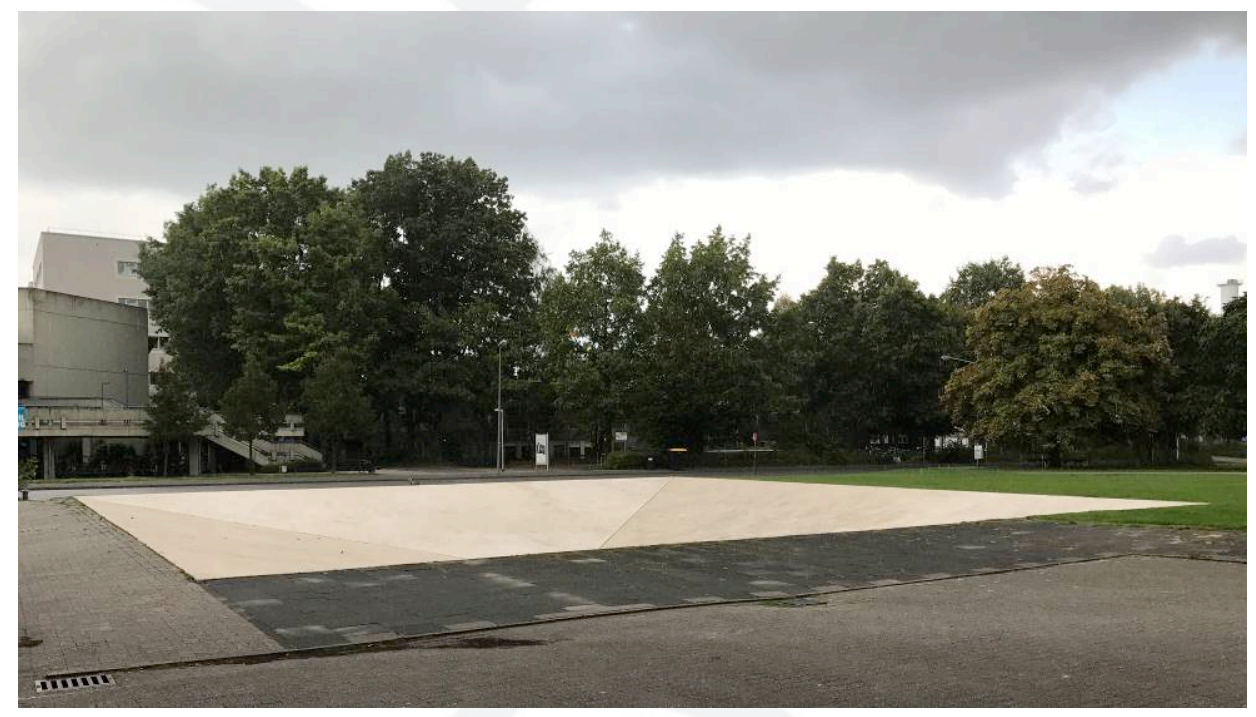

Figura 1: Square Depression, Bruce Nauman, 2007 Fonte: Mayra Santos, 2017. 
A OBRA

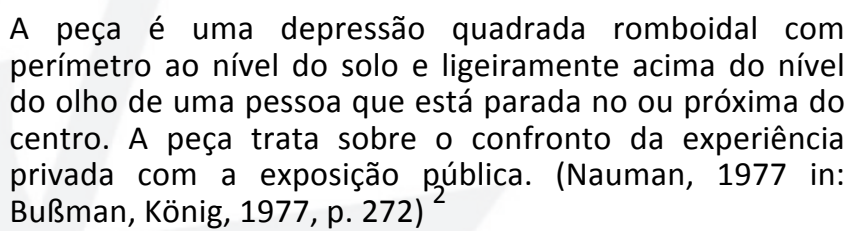

O projeto da Square Depression, originalmente feito em 1977 para o Skulptur Projekte em Münster, materializou-se somente em 2007. No breve texto escrito por Nauman dedicado à obra para o catálogo da exposição de 1977, existem dois aspectos a serem observados: primeiro a decisão sobre o posicionamento do nível central da peça, que está "ligeiramente acima do nível do olho de uma pessoa". A parte central a 2,3 metros de profundidade coloca qualquer pessoa de estatura mediana totalmente abaixo do nível do terreno, estando envolta por toda a peça. No centro, estamos completamente em contato com a escultura, percebendo-a na sua mais pura materialidade. A profundidade muda a percepção do espaço em relação ao campo de visão, diminui a visibilidade do entorno, aumentando a sensação de isolamento, desamparo e solidão que, de algum modo, a obra tenta promover. Estar no centro corresponde ao ápice da experiência sensorial pretendida, um ponto que conduz o público ao mais absoluto estado de introspecção. Daí o jogo da palavra Depression do título, que pode significar um estado psicológico, de estar à mercê de uma condição negativa, que a própria construção espacial pode causar; como também aludir ao seu sentido geográfico, de relevo de um terreno, que se traduz na forma de pirâmide invertida.

A outra questão é que "A peça trata sobre o confronto da experiência privada com a exposição pública". Esta afirmação de Nauman é sobre a experiência de cada um de nós, individual, ante a uma obra que nos faz involuntariamente revelar emoções em público ao caminharmos sobre ela. Quem entra está em relação

\footnotetext{
${ }^{2}$ Do original: "The piece is a rhomboid square depression with the perimeter at ground level and slightly above the eyelevel of a person standing at or near the center. The piece is about the confrontation of private experience with public exposure."
} 
direta com a escultura, participando dela. Aquele que se aproxima vê quem está sobre ela como parte de uma performance, como algo igualmente exposto, o que é revelado no próprio texto dos curadores: "Entrar, portanto, equivale a um desaparecimento, mas que é, na verdade, uma exposição também, pois a pessoa se move em um estágio negativo" (Frazen, König, Plath, 2007, p.173).

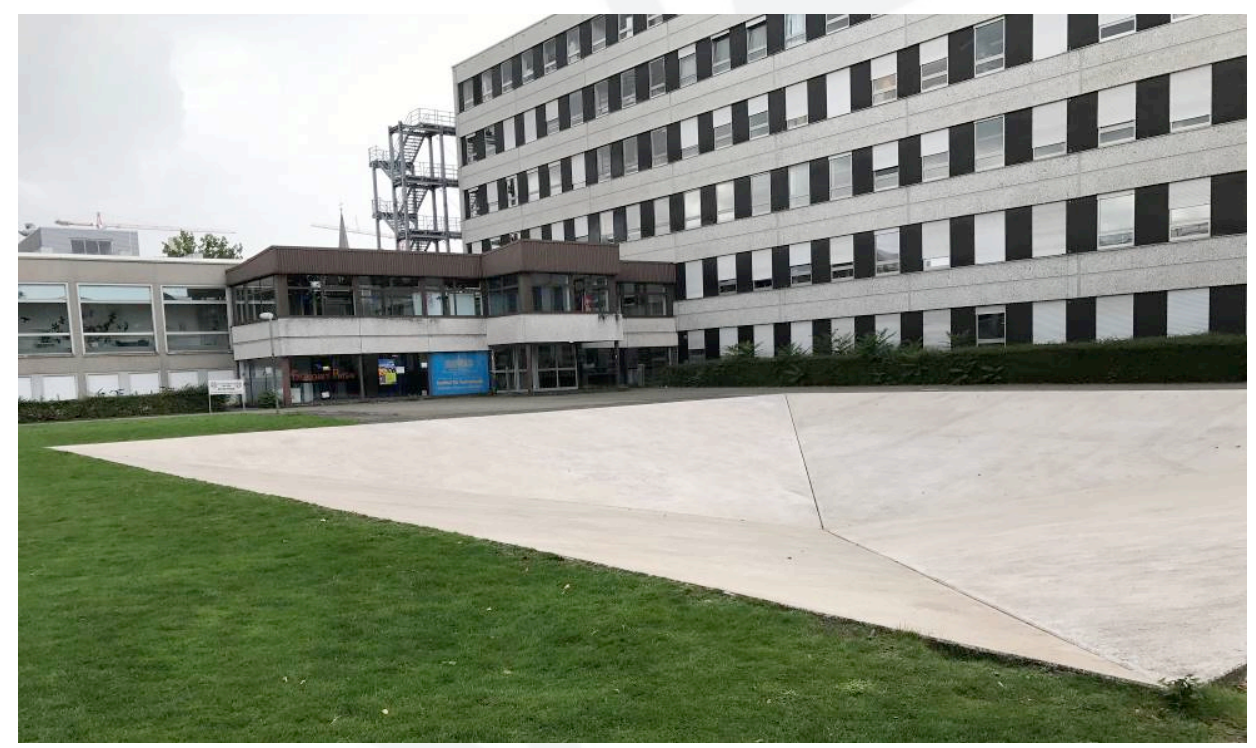

Figura 2: Square Depression, Bruce Nauman, 2007 Fonte: Mayra Santos, 2017.

No entendimento da curadoria, ao mesmo tempo em que somos abrigados pela escultura, tecnicamente protegidos pela depressão topográfica que nos coloca em uma condição negativa em relação ao nível do terreno, também estamos expostos no seu centro. Esta dupla experiência de alguma maneira gera uma tensão sobre os limites das dimensões públicas e privadas.

O primeiro Skulptur Projekte de Münster em 1977 propunha refletir sobre a seguinte questão: o que seriam obras de arte públicas contemporâneas? 0 sentido da palavra público em Münster passa tanto pela condição do espaço enquanto esfera pública, ou seja, num sentido democrático, quanto pela noção de destinatário da obra de arte, do grupo de pessoas que irá vivenciá-la. Podemos dizer que de alguma forma a proposta do projeto reflete sobre esta condição. Se entendermos o "Square" do título como praça, podemos imaginar 
a obra como um espelho de um espaço público, até por ocupar uma área frontal entre um edifício e a rua, atendendo ao chamado do projeto. Entretanto Nauman vai além, rebaixando o seu centro, o ápice do trabalho também se torna um anticlímax. O que nos faz retornar para a tensão que o espaço causa no visitante. Outras produções de Nauman também irão abordar o aspecto público, no sentido de ser pensado para o espectador, voltado à experiência do público, porém dentro do espaço privado institucional.

\section{O ARTISTA}

Bruce Nauman, desde que se formou na década de 1960 na Universidade de Wisconsin, produz obras em diversos meios na arte, tais como escultura, instalação, performance, vídeo, holografia, neon e desenhos ${ }^{3}$. No início de sua carreira, o artista confrontou-se com uma questão que nortearia seus trabalhos: "o que seria arte?". Percebeu que sendo artista e trabalhando dentro do estúdio, toda a sua produção poderia ser designada como arte, chegando à conclusão que o único problema seria como organizar esta produção para apresentá-la como tal (Nauman, 1988, in: Wood, Hulks, Potts, 2007, p.408). A partir disso passa a produzir vídeos, gravações dos experimentos que ocorriam dentro do estúdio, como por exemplo Dance or Exercise on the Perimeter of a Square, de 1967-68 no qual faz uma performance coreografada de passos definidos por uma marcação no piso; e Violin Tuned DEAD, de 1969, na qual o artista elabora um vídeo de si mesmo tocando violino de costas num determinado ritmo ${ }^{4}$. Contudo sua arte não se resumia nisso. A todo instante se perguntava sobre o que seria diferente e original, refletindo sobre o fazer artístico.

\footnotetext{
${ }^{3}$ A análise deste artigo parte de um conjunto de trabalhos de Bruce Nauman para compreender a obra Square Depression, não limitando sua trajetória. Para uma leitura mais abrangente recomendamos a tese de doutoramento de Liliane Benetti, Ângulos de uma caminhada lenta: exercícios de contenção, reiteração e saturação na obra de Bruce Nauman, citada na bibliografia.

${ }^{4}$ As imagens das obras citadas ao longo do artigo podem ser vistas no livro Please pay attention please: Bruce Nauman's Words de Bruce Nauman e Janet Kraynak citado na bibliografia.
} 
Lembro-me, em certo momento, de pensar que algum dia eu descobriria como você faz isso, como você faz arte "Qual é o procedimento aqui, pessoal?" - e então não seria mais uma luta. Mais tarde, percebi que nunca seria assim, sempre seria uma luta. Eu percebi que nunca teria um processo específico. Eu teria que reinventá-lo, uma e outra vez. (Nauman, 1988 in: Wood, Hulks, Potts, 2007, p. 406) ${ }^{5}$

Get out of my mind Get out this room, de 1968, é uma obra de uma série de instalações artísticas, incluindo corredores e salas, que o artista produz no final dos anos 60 e início dos anos 70, em que som, luz e vídeo são incorporados no ambiente e o público é convocado a caminhar e perceber o espaço, num tom performático. Nesta obra o público adentra uma sala onde são emitidos os sons gravados do artista falando o título da instalação em vários tons, deixando o público aturdido ao envolvê-lo em um campo de ações ambivalentes: permanecer na sala e absorver a obra ou atender o chamado de saída.

Outra instalação é a Corridor Installation, de 1970, que tem sua origem no vídeo Walk with Contrapposto de 1968, para o qual constrói duas paredes paralelas, com distância entre elas de $51 \mathrm{~cm}, 2,44$ metros de altura por 6,10 metros de extensão, remetendo a um corredor estreito. No vídeo o artista caminha por este corredor, movimentando os quadris de forma estilizada, com as mãos cruzadas atrás do pescoço. Para Benetti (2013, p. 100) ao criar um dispositivo de restrição e compressão para o corpo, dificultando seu desempenho, o artista incorpora as paredes à coreografia, realçando as torções do seu corpo. Em 1969 ele transfere pela primeira vez esta experiência para o Museu Whitney, sob o nome Performance Corridor, construindo um espaço similar ao do vídeo e deixando ao público a possibilidade de entrar e experenciar, sob a condição de que entrasse um único individuo por vez. Para Nauman esta peça foi importante, pois a partir dela surge a ideia de fazer uma peça participativa, sem que os participantes fossem capazes de alterar o

\footnotetext{
${ }^{5}$ Do original: "I remember at one point thinking that someday I would figure out how you do this, how you do art - like, "What's the procedure here, folks?" - and then it wouldn't be such a struggle anymore. Later I realized it was never going to be like that, it was always going to be a struggle. I realized it I would never have specific process; I would have to reinvent it, over and over again."
} 
trabalho (Nauman, Kraynak, 2005, p.114). Em Corridor Installation (Nick Wilder Installation) de 1970, uma das extremidades do corredor é fechada onde estão instalados dois monitores, um passando o vídeo do corredor vazio e outro mostrando a imagem de quem o percorre. 0 espaço é pequeno e repressivo, sem dar margem às interpretações e sensações diferentes da que o autor queria causar. A partir deste conceito foram construídas algumas versões destes corredores em galerias e museus, alguns mais largos, outros mais estreitos, uns com espelho no final, outros com luzes piscantes, como por exemplo em Green Light Corridor, 1970, Corridor with Mirror and White Lights (Corridor with reflected Image), 1971, e Kassel Corridor, 1972.

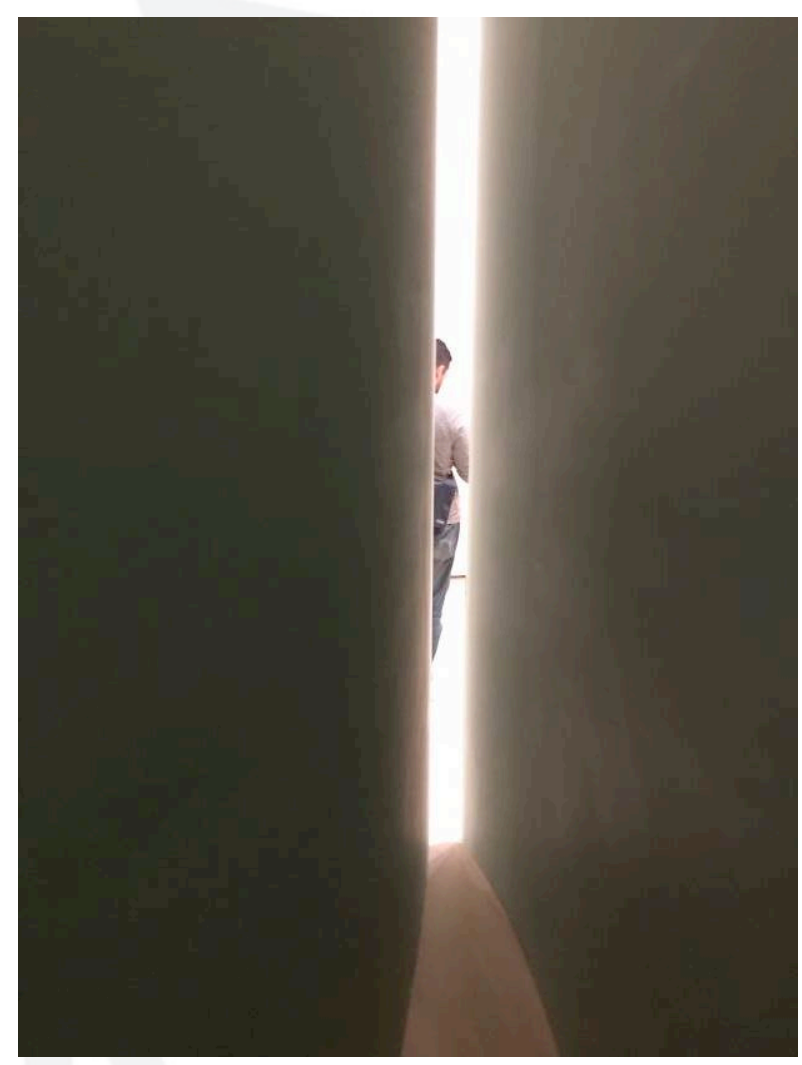

Figura 3: Kassel Corridor, Bruce Nauman, 1972. Foto da exposição Bruce Nauman: Disappearing Acts no MoMA em Nova lorque. Fonte: Liene Bosquê, 2019.

Nestas obras o papel do público constitui parte de sua essência: cada movimento é previsto e analisado pelo artista de forma a controlar suas ações no ambiente. A importância do corpo nas obras de Nauman pode ser vista 
desde as suas performances gravadas em videotape, nas quais podemos perceber a cadência de seus movimentos, numa busca por um ritmo próprio. Sobre isso, o artista comenta em entrevista concedida a Lorraine Sciarra em 1972 que no início era como gravar uma certa atividade, um exercício, mas depois com a reflexão sobre o tema, especialmente a partir da leitura do livro Gestalt Therapy e discussões com a artista performática e coreógrafa Meredith Monk, passou a ter mais consciência do corpo e a entender sua obra também como uma dança, algo parecido com trabalhos que o coreógrafo e bailarino Merce Cunningham havia realizado (Nauman in: Nauman, Kraynak, 2005, p.166). Esses exercícios de equilíbrio, com o passar do tempo, foram pensados como problemas de dança, sem que o artista fosse propriamente um bailarino. Para Benetti (2013, p.85) o artista buscava um movimento que fosse expressivo em si, sem que para isto dramatizasse à exaustão o que estes movimentos provocavam.

Logo, a posição, o movimento e a interação do público tornam-se elementos necessários ao reconhecimento e consciência do próprio espaço. Por isso a preocupação do artista em manter o controle sob esta experiência, seja por meio dos limites impostos pelo próprio espaço ou até mesmo por meio de instruções escritas dadas pelo artista, descrevendo a melhor forma de compreender os propósitos de seus trabalhos. Dado um conjunto de instruções, as pessoas sentem-se compelidas a responder a certo tipo de interpretação, não necessariamente limitando-as, mas induzindo-as a participar de uma situação controlada.

Eu acho que se você pode controlar a situação fisicamente, então você pode ter uma certa quantidade de semelhança. As pessoas são suficientemente semelhantes para que você possa ter pelo menos um tipo semelhante de experiência. Mas, certamente, a coisa privada pode mudar bastante a experiência de algumas maneiras, não espere ser capaz de controlar isso. Mas, por outro lado, não gosto de deixar as coisas abertas para que as pessoas sintam que estão em uma 
situação com a qual podem jogar. (Nauman in: Nauman, Kraynak, 2005, p. 182)

\section{A FORMA BRANCA}

Em Square Depression, até pelo contraste cromático da grama com o concreto branco, há uma clareza entre o ato de contemplar a escultura e participar efetivamente dela, do estar fora e estar dentro. Pode-se entender que a condição de estar dentro é parte da proposta artística no que diz respeito à ideia de ficar exposto. Com essa exceção, pouco é determinado pelo artista e, de certo modo, as ações são livres. Por estar inscrita num espaço público e aberto, podemos supor que o artista tem menos controle sobre as ações. Neste caso, o caráter público é imanente, e parece possível apropriar da obra de outros modos. Pode-se, por exemplo, caminhar, sentar e descansar ou até mesmo andar de bicicleta ou skate. Ainda que sem uma instrução clara de como experenciar a obra, intuitivamente, o artista conduz o público ao seu centro. A instrução está implícita no seu formato, na inclinação de seus planos, onde a direção do movimento vai ao encontro da centralidade. Caminhar até seu centro e olhar ao redor parece parte do protocolo.

Square Depression foi somente construída em 2007, visto que o projeto na época foi desaprovado pelas autoridades locais, enfrentando também problemas de financiamento. Nestes trinta anos até sua construção pouca coisa mudou com relação ao projeto original, exceto a alteração do sistema de drenagem de água. Seus croquis e desenhos dão foco à forma abstrata projetada por quatro triângulos isósceles incorporados ao solo em profundidade, com inclinação de 10 graus. Os triângulos são separados por um

\footnotetext{
${ }^{6}$ Do original: "I think that if you can control the situation physically, then you can have a certain amount of similarity. People are sufficiently similar so that you can have at least a similar kind of experience. But, certainly, the private thing can change the experience a great deal in some ways, and I don't expect to be able to control that. But, on the other hand, I don't like to leave things open so that people feel they are in a situation they can play games with."
} 
vão sutil de $2 \mathrm{~cm}$, que auxilia na drenagem e faz transparecer a geometria da peça escultórica. Uma forma limpa e pura, autorreferente.
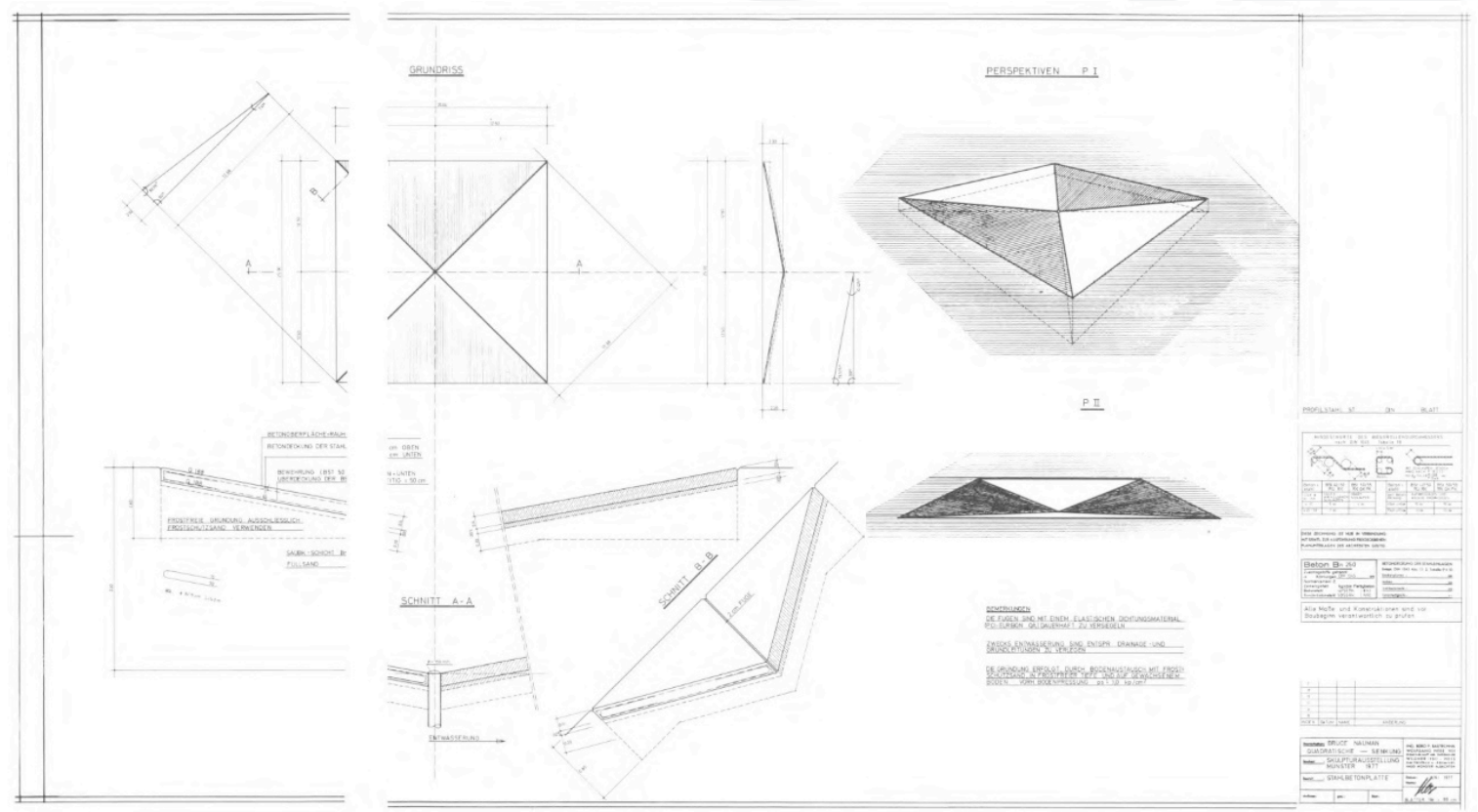

Figura 4: Projeto para Square Depression, com detalhes sobre estrutura, 1977. Fonte: BUßMAN, KÖNIG, 1977, p. 273-274. Crédito: LWL-Museum für Kunst und Kultur, Westfälisches Landesmuseum, Münster.

Figura 5: Desenho Square Depression, 1976. Fonte: BUßMAN, KÖNIG, 1977, p. 276. Crédito: LWL-Museum für Kunst und Kultur, Westfälisches Landesmuseum, Münster. 
Além disso, os desenhos de Square Depression nos fazem pensar no inverso, no espaço vazio de uma pirâmide. Essa questão do espaço negativo já havia sido tema de seus trabalhos anteriores, como por exemplo em A Cast of the Space under My Chair, 1965-68. Nessa obra, o artista reconstrói em concreto o espaço vazio embaixo de uma cadeira, transformando o espaço negativo em um espaço útil, subvertendo o sentido funcional do objeto e criando assim um novo simbolismo. Nauman também moldou com resina e fibra de vidro o espaço entre duas caixas no chão em Platform Made Up of the Space Between Two Rectilinear Boxes on the Floor, 1966. A moldagem desses espaços negativos influenciou o trabalho de alguns artistas, como o de Rachel Whiteread (Simon, 1988, in: Wood, Hulks, Potts, 2007, p. 405), e mais especificamente o trabalho Untitled (One Hundred Spaces), 1995, na qual a artista moldou em resina o espaço negativo debaixo de 100 cadeiras.

Colocar o espaço debaixo de uma cadeira foi a versão escultórica da declaração de De Kooning: "Quando você pinta uma cadeira, deve pintar o espaço entre as travessas, não a cadeira em si." Eu estava pensando assim: sobre sobras e espaços negativos. Espaço negativo para mim é pensar no lado inferior e no lado de trás das coisas. (Nauman in: Wood, Hulks, Potts, 2007, p. 409) ${ }^{7}$

${ }^{7}$ Do original: "Casting the space under a chair was the sculptural version of de Kooning's statement: 'When you paint a chair, you should paint the space between the rungs, not the chair itself'. I was thinking like that: about leftovers and negative spaces." 
Sob a perspectiva de Square Depression, podemos compreender que a escultura mantém relação com este conceito: ao refletir no negativo de uma pirâmide, inverte sua forma e realiza um espaço que convida, recebe e acolhe o público. Essa estratégia em todo caso não elimina a imagem oposta, fica no imaginário de quem vê, como se a escultura fosse uma reminissência de uma construção.

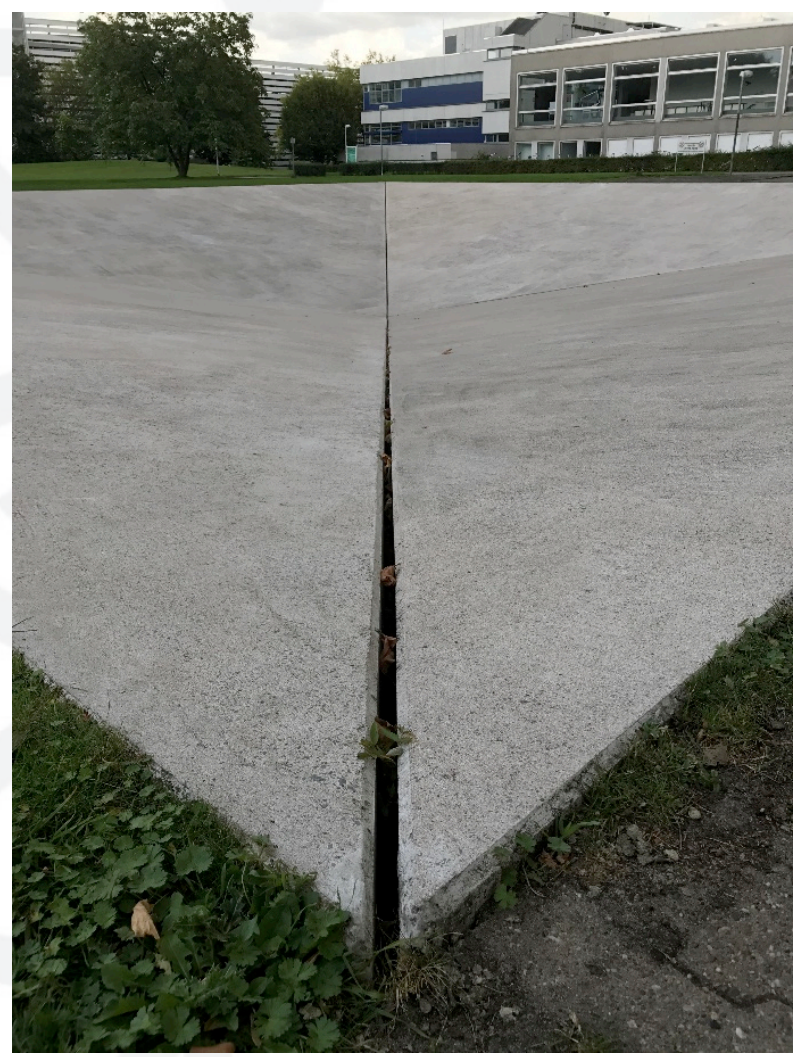

Figura 6: Square depression, Bruce Nauman, 2007. Fonte: Mayra Santos, 2017

Nos anos 1970 Nauman trabalha em algumas esculturas, chamadas de obras arquitetônicas híbridas por Janet Kraynak (in Nauman, Kraynak, 2005, p.187) ou de instalações arquitetônicas por Joan Simon (in Wood, Hulks, Potts, 2007, p.411). Estas obras são compostas por salas e corredores, que mostram a busca do artista 
pela produção de grandes espaços físicos, até o momento inscritas dentro de museus e galerias. Já no final dos anos 1970 o artista reflete sobre como produzir obras numa escala maior. Em 1978 na Ace Gallery em Vancouver, expôs modelos em escala reduzida de esculturas que poderiam ser instaladas ao ar livre, algumas das quais com a proposta de serem enterradas no subsolo como rampas e passagens, fornecendo caminhos para o espectador (Nauman, Kraynak, 2005, p.185-186). Num primeiro momento o espectador apreendia a peça na dimensão que se apresentava, dentro do espaço da galeria e num segundo momento, sabendo que estava ali em escala reduzida, tentava imaginar a dimensão proposta. Novamente o artista promove uma tensão entre as duas informações, gerando experiências divergentes. Segundo o artista, a informação que torna estas obras interessantes é o fato de que o espectador começa a imaginar como seria e como responderia a uma escala adequada, mesmo sabendo que o que está sendo apresentado, a escultura, é apenas um modelo (Nauman, Kraynak, 2005, p.187). Então há as duas ideias que cabem na obra, a de escultura e a de modelo. É importante salientar que mesmo sendo um modelo, o conceito da obra é norteado pela ideia de espaço público, de pertencer a um espaço aberto, fora do espaço institucional. Ou seja, foram obras pensadas para serem construídas.

Minha intenção era lidar com a relação do espaço público com o espaço privado. Quando você está sozinho, você aceita o espaço, amaldiçoando-o com a sua presença; assim que alguém aparecer, você se retira e se protege. 0 outro representa uma ameaça, você não quer lidar com isso. O melhor exemplo disso é quando alguém sai de uma rua movimentada e entra em uma cabine telefônica. Por um lado, você entra lá para obter privacidade acústica e, por outro lado, torna-se uma figura pública. É um tipo de situação conflitante. O que eu quero fazer é usar a polaridade investigativa que existe na tensão entre o espaço público e privado e usá-lo para criar uma vantagem. (Nauman in: Nauman, Kraynak, 2005, p. 187) ${ }^{8}$

\footnotetext{
${ }^{8}$ Do original: "My intention was to deal with the relationship of public space to private space. When you are alone, you accept the accept the space by filing it with your presence; as soon as someone else comes into view, you withdraw and protect yourself. The other poses a threat, you don't want to deal with it. The best example of this is when someaone steps out of a crowded street and into a phone booth. On the one hand you go in there to get acoustic privacy and on the other hand you make yorself a public figure. It is a conflicting kind of situation. What I want to do is use the investigative polarity that exists in the tension between the public and private space and use it to create na edge."
} 
Outro ponto importante, lembra Benetti (2013, p. 110) é que estas instalações arquitetônicas, ao mesmo tempo que são idealizadas enquanto intervenções na escala urbana, não são feitas para interferir na paisagem, uma vez que são construções enterradas ou subterrâneas. Nesse sentido, as obras deixam de ser vistas como marcos, para ser vivenciadas pelo público. Um exemplo desta abordagem é Model for Trench and Four Buried Passages, de 1977, um modelo de uma peça subterrânea feita de gesso e fibra de vidro que evoca a imaginação ao mesmo tempo que possui uma presença escultural.

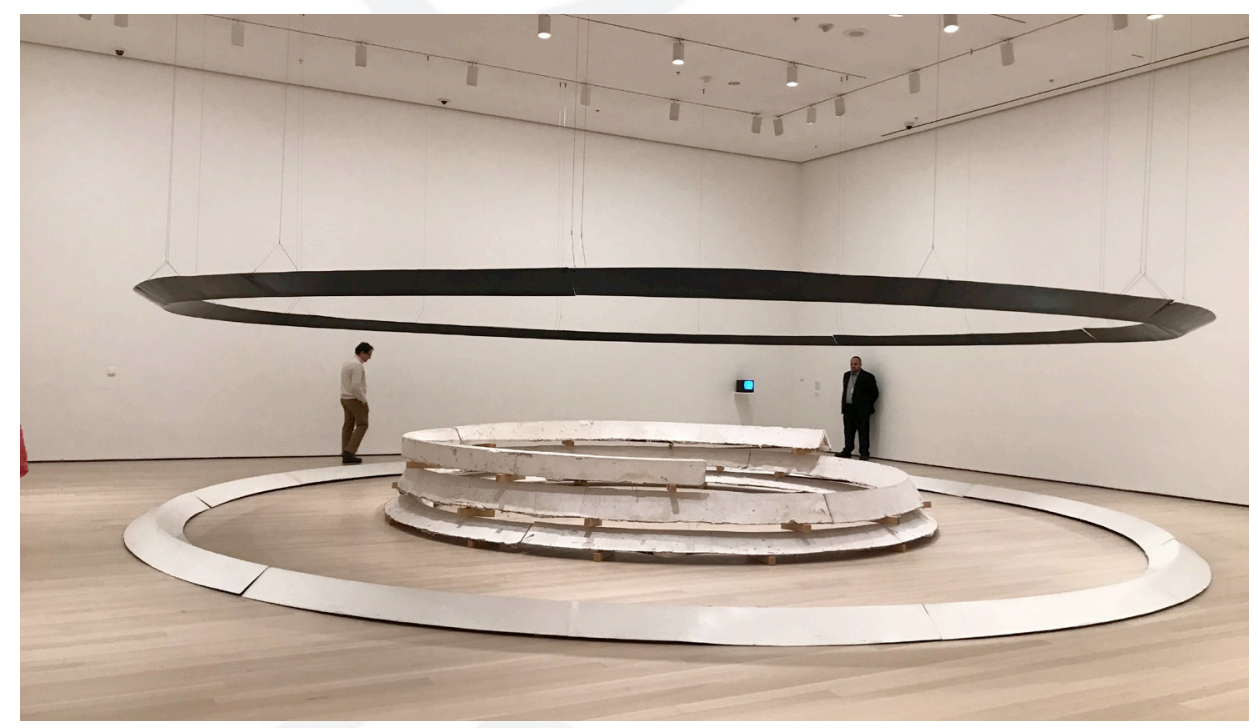

Figura 7: Model for Trench and Four Buried Passages, Bruce Nauman, 1977. Foto da exposição Bruce Nauman: Disappearing Acts no MoMA em Nova lorque. Fonte: Liene Bosquê, 2019.

Portanto, se tentarmos imaginar os conceitos que nortearam Square Depression diríamos que há uma busca pelo espaço negativo, com a construção dos planos inclinados enterrados para que o público pudesse ser induzido a caminhar e experenciar, como acontece naturalmente em um espaço público. Podemos entender que Square Depression está ligada a estas obras apresentadas na Ace Gallery em Vancouver em 1978 e que talvez tenha sido a única desta série a ser construída, mesmo que trinta anos depois. 


\section{CONCLUSÃO}

Para o curador Kasper König, após trinta anos, fecha-se um ciclo: "Quando Bruce Nauman projetou o trabalho em 1977, ele estava muito à frente de seu tempo. A pirâmide invertida não perdeu nada da sua relevância nos últimos 30 anos" (König, Press release, 2007).

"Um pensamento em afundar, os triângulos afundados, é que você pode correr e ser tão fundo que o nível dos olhos está abaixo do nível do solo. (...) Todo mundo está acima de você e olhando para você. Essa foi a origem da ideia", descreve o artista em 2007 (Nauman, Press release, 2007), que confirma a ideia de induzir a pessoa em direção ao centro, no sentido de expô-la no espaço dado.

Voltamos então a ideia dos planos inclinados, da construção da topografia. 0 público deve responder fisicamente à profundidade da escultura, se posicionando dentro ou fora, seja atravessando-a ou caminhando em torno dela. Ver a peça e percebê-la com o corpo se tornam uma experiência contínua e o comportamento e os gestos decorrentes mudam em virtude do seu posicionamento. $\mathrm{O}$ corpo passa a ser um agente, um elemento chave para a compreensão da escultura de Nauman.

Nas construções espaciais arquitetônicas, seja no ambiente externo urbano, seja nos espaços internos, os caminhos nos levam a ver e perceber a profundidade e a qualidade do ambiente. Entre o posicionamento e o movimento reconhecemos e vivenciamos o espaço, embora invariavelmente a urgência do cotidiano nos impeça de lê-lo com outros olhos.

A escultura pública de Nauman é um espaço transgressor e complexo. Entrar em Square Depression representa um caminhar induzido, em que se misturam sentimentos de proteção e exposição. A hibridez tão latente neste trabalho nos faz pensar em outros modos de ver e perceber o espaço. A praça rampada 
de acesso ao Centro Georges Pompidou tem função inerente ao seu programa, em ser um ambiente público de acolhimento e fluxo. Ao mesmo tempo, nos faz apreender o edifício e seu entorno com outro olhar. É nesse sentido que, proponho, a obra arquitetônica e a obra artística podem se aproximar, no modo que confrontamos e apreendemos o espaço. Square Depression é uma escultura pública. Sua experiência resultante vai além, ultrapassando a funcionalidade, e resistindo a pressupostos além do pensamento criativo do próprio artista. Uma obra que trata o espaço do ponto de vista crítico, entre tensões e anseios que sua experiência é capaz de provocar.

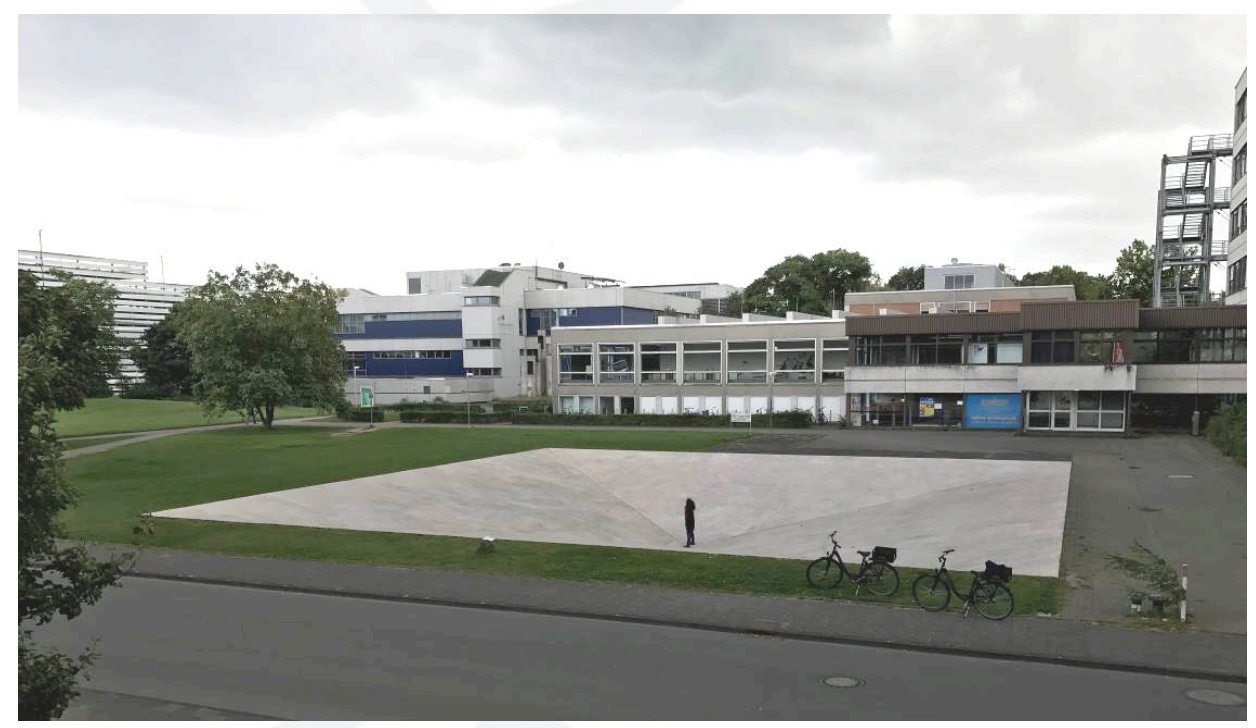

Figura 8: Square depression, Bruce Nauman, 2007. Fonte: Mayra Santos, 2017

\section{BIBLIOGRAFIA}

Benetti, Liliane. Ângulos de uma caminhada lenta: exercícios de contenção, reiteração e saturação na obra de Bruce Nauman. Tese de doutorado. Programa de pós-graduação em Artes Visuais - Escola de Comunicação e Artes, Universidade de São Paulo. São Paulo, 2013.

Bußman, Klaus; König, Kasper (org.). Skulptur Ausstellung in Münster 1977. Katalog I und II, Münster: Hölker, 1977.

Franzen, Brigitte; König, Kasper; Plath, Carina (eds.), Skulptur Projekte Münster 07, exhibition catalogue. Münster, Cologne: LWL-Landesmuseum für Kunst und Kulturgeschichte, 2007. 
Nauman, Bruce; Kraynak, Janet (ed). Please pay attention please: Bruce Nauman's Words. Writings and Interviews. Cambridge: The MIT Press, 2005

Wood, J.; Hulks, D.; Potts, A. Modern sculpture reader. Leeds: Henry Moore Institute, 2007

\section{Fontes eletrônicas e sites}

Press realease. Skulptur Projekte Münster 07. 05/06/2007. "Square Depression" von Bruce Nauman: Eine negative Bühne zur Selbsterfahrung. Disponível em: <http://www.skulptur-projekte.de/archiv/07/www.skulpturprojekte.de/skulptur-projekte-download/pdf/PM_Nauman_5.6.07.pdf>. Acessado em 10 de agosto de 2019. 